\title{
REVIEW
}

\section{Molecular and clinical insights from studies of calcium-sensing receptor mutations}

\author{
Caroline M Gorvin'1,2,3 \\ IInstitute of Metabolism and Systems Research (IMSR), University of Birmingham, Birmingham, UK \\ ${ }^{2}$ Centre of Membrane Proteins and Receptors (COMPARE), University of Birmingham, Birmingham, UK \\ ${ }^{3}$ Centre for Endocrinology, Diabetes and Metabolism (CEDAM), Birmingham Health Partners, Birmingham, UK \\ Correspondence should be addressed to C M Gorvin: C.Gorvin@bham.ac.uk
}

\begin{abstract}
Twenty-five years have elapsed since the calcium-sensing receptor (CaSR) was first identified in bovine parathyroid and the receptor is now recognized as a fundamental contributor to extracellular $\mathrm{Ca}^{2+}\left(\mathrm{Ca}^{2+}{ }_{\mathrm{e}}\right)$ homeostasis, regulating parathyroid hormone release and urinary calcium excretion. The CaSR is a class C G-protein-coupled receptor (GPCR) that is functionally active as a homodimer and couples to multiple G-protein subtypes to activate intracellular signalling pathways. The importance of the CaSR in the regulation of $\mathrm{Ca}^{2+}{ }_{e}$ has been highlighted by the identification of $>400$ different germline loss- and gain-of-function CaSR mutations that give rise to disorders of $\mathrm{Ca}^{2+}{ }_{\mathrm{e}}$ homeostasis. CaSR-inactivating mutations cause neonatal severe hyperparathyroidism, characterised by marked hypercalcaemia, skeletal demineralisation and failure to thrive in early infancy; and familial hypocalciuric hypercalcaemia, an often asymptomatic disorder associated with mild-moderately elevated serum calcium concentrations. Activating mutations are associated with autosomal dominant hypocalcaemia, which is occasionally associated with a Bartter's-like phenotype. Recent elucidation of the CaSR extracellular domain structure enabled the locations of CaSR mutations to be mapped and has revealed clustering in locations important for structural integrity, receptor dimerisation and ligand binding. Moreover, the study of disease-causing mutations has demonstrated that CaSR signals in a biased manner and have revealed specific residues important for receptor activation. This review presents the current understanding of the genetic landscape of CaSR mutations by summarising findings from clinical and functional studies of diseaseassociated mutations. It concludes with reflections on how recently uncovered signalling pathways may expand the understanding of calcium homeostasis disorders.
\end{abstract}

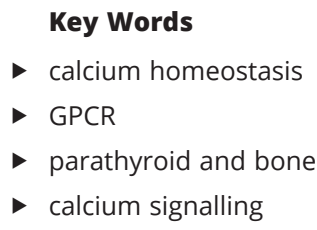

Journal of Molecular Endocrinology (2019) 63, R1-R16

\section{Discovery of the calcium-sensing receptor}

The significance of the parathyroid in calcium homeostasis has been recognised for more than 100 years. Early investigations demonstrated that removal of the parathyroid glands induces acute hypocalcaemia in humans and animals and that intravenous injection of parathyroid gland extract or parathyroid hormone (PTH) normalises serum calcium levels (Conigrave 2016). Several decades later, isolated dispersed human parathyroid cell cultures were used to show that exogenous treatment with $\mathrm{Ca}^{2+}$ or $\mathrm{Mg}^{2+}$ robustly reduced PTH secretion, leading to the proposal that parathyroid cells harbour a $\mathrm{Ca}^{2+}$ sensor (Conigrave 2016). The molecular details of this 
calcium-sensing mechanism began to be uncovered in the late 1980s with the demonstration that divalent cations could induce inositol trisphosphate $\left(\mathrm{IP}_{3}\right)$ generation and transient increases in intracellular calcium $\left(\mathrm{Ca}^{2+}{ }_{\mathrm{i}}\right)$ in parathyroid cells, likely by a cell-surface receptor (Nemeth \& Scarpa 1987, Shoback et al. 1988). Finally, in 1993 , a $5.3 \mathrm{~kb}$ clone, predicted to encode a protein of the G-protein-coupled receptor (GPCR) superfamily, was isolated from bovine parathyroid that when expressed in Xenopus oocytes had pharmacological properties similar to those of the calcium-sensing protein previously described in parathyroid cells (Brown et al. 1993). Subsequently, orthologs of the protein, now known as the calcium-sensing receptor (CaSR), were cloned from several mammalian species, including humans and from a variety of tissues (Conigrave 2016).

\section{Structure and activation of CaSR}

We now understand the CaSR to be a class C GPCR, comprising 1078 amino acids, that primarily exists at cell surfaces as a disulphide-linked homodimer. Two crystal structures of the CaSR extracellular domain (ECD) were published in 2016 and uncovered details of the receptor activation mechanism, which shares similarities with the related metabotropic glutamate receptors (mGluRs) and $\mathrm{GABA}_{\mathrm{B}} \mathrm{R}$ (Geng et al. 2016). The ECD (amino acids 1-610) comprises a bi-lobed venus fly-trap domain (VFTD) and a cysteine-rich domain (CRD) (Geng et al. 2016, Zhang et al. 2016) (Fig. 1). In the inactive state, the two CaSR protomers interact primarily at the lobe 1-lobe 1 interface. On activation, each protomer undergoes a $29^{\circ}$ rotation, bringing the Lobe 2-Lobe 2 and CRD-CRD domains into closer proximity and expands the homodimer interface (Geng et al. 2016) (Fig. 1). Interactions across the homodimer occur at several sites and play a critical role in structural integrity and receptor activation. In the inactive state, these include two loops that are unique to CaSR (Fig. 1). Loop 1 stretches across the dimer interface from lobe 1 of one protomer to interact with a hydrophobic surface on the other protomer (Geng et al. 2016, Zhang et al. 2016). In loop 2, two $\alpha$-helices at the top of lobe 1 reach across the interprotomer region to stabilise dimerization. This loop involves intermolecular disulfide bonds between two highly conserved cysteine residues (Cys129 and Cys131) and a surrounding hydrophobic region (Geng et al. 2016, Zhang et al. 2016).

The CaSR transmembrane domain (TMD, amino acids 611-863) comprises seven transmembrane helices, three extracellular loops (ECL1-3) and three intracellular loops (ICL1-3), and mediates G-protein activation, while amino acids 864-1078 form the intracellular domain (ICD), which can interact with several proteins that modulate CaSR signalling and cell-surface expression (Bai et al.
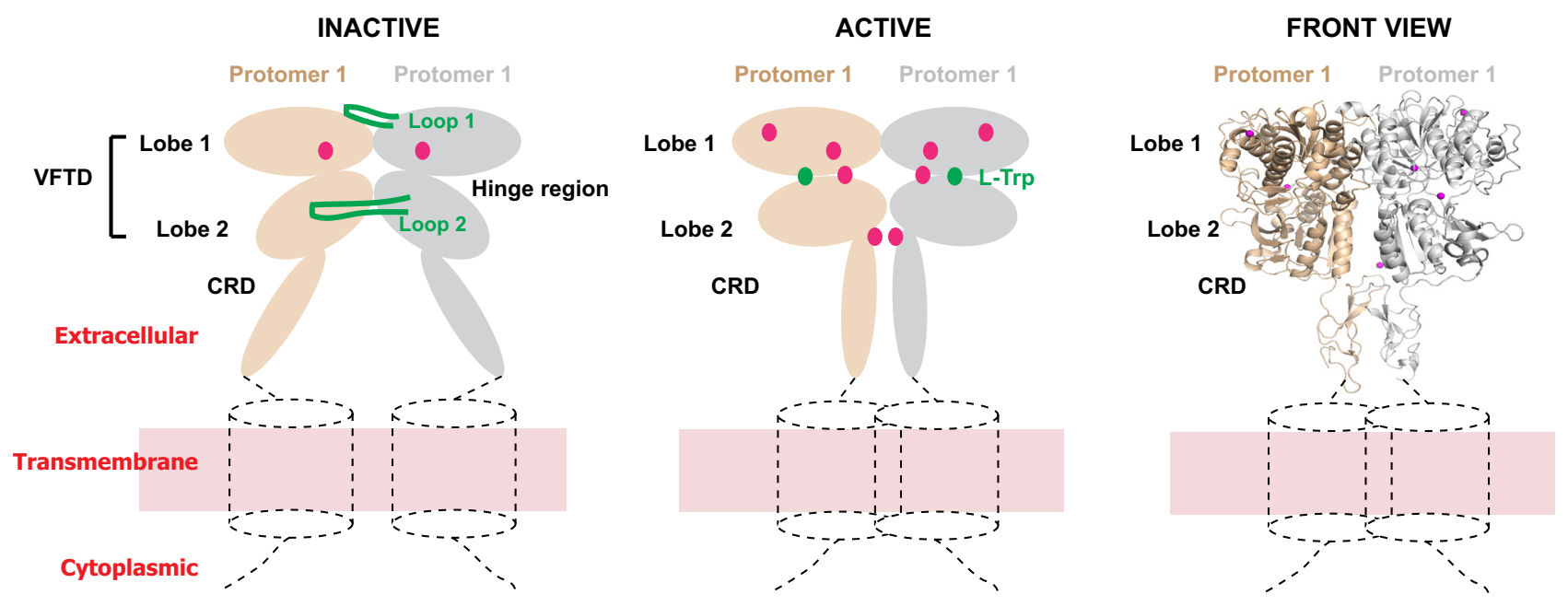

\section{Figure 1}

Schematic diagram showing the structure and activation mechanism of CaSR. All panels focus on the ECD as two crystal structures of this region have been published (Geng et al. 2016, Zhang et al. 2016). The TMD and ICD are shown by hatched outline to depict where these regions are positioned. The left and middle images show the inactive and active states in cartoon form, and the image to the right, the crystal structure of the ECD in front view, on which the cartoons are based (PDB:5K5S) (Geng et al. 2016). The receptor exists primarily at cell surfaces as a homodimer and each protomer ECD comprises a bi-lobed venus flytrap domain (VFTD) and a cysteine-rich domain (CRD). In the inactive state, homodimer interactions occur predominantly at the lobe 1 -lobe 1 interface and at loop 1 and 2. On receptor activation, each protomer undergoes a $29^{\circ}$ rotation, bringing the Lobe 2 -Lobe 2 and CRD-CRD domains into closer proximity and expanding the homodimer interface. Pink spheres show Ca²+-binding sites and green spheres L-Trp-binding sites. Loops 1 and 2 are only shown on the inactive cartoon. 
1998, McCullough et al. 2004, Zhang \& Breitwieser 2005). Upon ligand binding CaSR activates multiple signalling pathways by coupling to several G-protein subtypes, but predominantly utilises the $\mathrm{G}_{\mathrm{i} / \mathrm{o}}$ pathway to suppress cAMP and activate mitogen-activated protein kinase (MAPK) cascades and the $\mathrm{G}_{\mathrm{q} / 11}$ pathway, that activates $\mathrm{Ca}^{2+}{ }_{\mathrm{i}}$ mobilisations and MAPK signalling (Conigrave 2016).

\section{Mutations in the CaSR cause disorders of calcium homeostasis}

Following its molecular cloning, the importance of CaSR in regulating $\mathrm{Ca}^{2+}{ }_{\mathrm{e}}$ homeostasis was confirmed by the discovery that germline-inactivating mutations in the receptor cause two hypercalcaemic disorders, neonatal severe hyperparathyroidism (NSHPT) and the milder familial hypocalciuric hypercalcaemia type-1 (FHH1) (Pollak et al. 1993, 1994), while activating mutations cause autosomal dominant hypocalcaemia type-1 (ADH1). In the 25 years that have elapsed since CaSR was cloned, more than 400 different human mutations have been described, and studies of these mutant proteins have provided important molecular insights into how the receptor is activated and mediates signalling. Within this review I will discuss some lessons we have learnt by studying these mutations, from clinical presentation to molecular mechanisms of receptor activation. Inclusion of all reported CaSR mutations within this review would be impossible, and therefore, they are listed in Supplementary Table 1 (see section on supplementary data given at the end of this article).

\section{Neonatal severe hyperparathyroidism (NSHPT)}

NSHPT (OMIM:239200) is a rare disorder in which affected infants present with marked hypercalcaemia, skeletal demineralisation and failure to thrive, and can be fatal if left untreated (Pollak et al. 1993). Observations of the coincidence of NSHPT and FHH1 in families, and parental consanguinity in many NSHPT kindreds, led investigators to suspect NSPHT was caused by homozygous mutations, while the milder FHH1 arose from heterozygous mutations of the same gene. Initial genetic investigations were consistent with this hypothesis and studies of a CaSR-knockout mouse model, in which homozygous mice have markedly elevated serum calcium and PTH, parathyroid hyperplasia, retarded growth and premature death, while heterozygous mice have mild hypercalcaemia
(Ho et al. 1995), consistent with NSHPT and FHH, respectively, seemingly provided further evidence of this genetic dosage effect. However, while most of the $\sim 45$ described cases of NSHPT are due to homozygous $(\sim 75 \%)$ or compound heterozygous mutations ( 10\%), several cases of NSHPT have been described in patients with heterozygous mutations of CaSR (Supplementary Table 1). The six mutations reported in these patients (Arg185Gln, Arg227Leu, Arg551Lys, Ile555Thr, Cys582Tyr and Ser591Cys) occur in the ECD of the CaSR and are located in regions that are critical for receptor activation (Geng et al. 2016, Zhang et al. 2016) (Fig. 2A). These include the hinge region between lobes 1 and 2 (Arg185), the lobe 2 homodimer interface (Arg227) and the CRD homodimer interface (Ile555 and Arg551), while the Cys582 and Ser591 residues are also located within the CRD (Geng et al. 2016, Zhang et al. 2016) (Fig. 2A). These three regions undergo the largest conformational changes during transition from the inactive to the active state, and several of these residues form critical agonist-induced homodimer contacts upon receptor activation (Geng et al. 2016, Zhang et al. 2016). The heterozygous NSHPT mutant residues are predicted to disrupt these contacts and have been shown in vitro to severely impair receptor responses, despite normal cell-surface expression (Bai et al. 1996, Wystrychowski et al. 2005, Toke et al. 2007).

However, these are not the only mutations to occur in these critical regions. Indeed, FHH1 mutations have been reported in several of these residues, and it is therefore unlikely that the location of the residue per se determines whether a patient presents with NSHPT or FHH1. How mutations in a single residue cause the two different disorders has been examined for the Arg227 residue, demonstrating that the Arg227Leu mutation, which causes NSHPT, has a more severe impairment in receptor signalling compared to a mutation in the same residue, Arg227Gln, which causes FHH1 (Wystrychowski et al. 2005). Therefore, for this residue at least, there appears to be a genotype-phenotype correlation to explain the differences in clinical presentation. Yet, this is not consistent for all NSHPT heterozygous mutant residues as some mutations have been shown to cause NSHPT in one patient, while other patients have presented with FHH1 (Supplementary Table 1) (Nyweide et al. 2006, Reh et al. 2011, Taki et al. 2015). Intrauterine exposure to maternal calcium and vitamin D, and the presence of other CaSR polymorphisms that could act as genetic modifiers to influence receptor activity, could explain the discrepancies of clinical presentation in some heterozygous patients (Toke et al. 2007, Reh et al. 2011, Taki et al. 2015). 

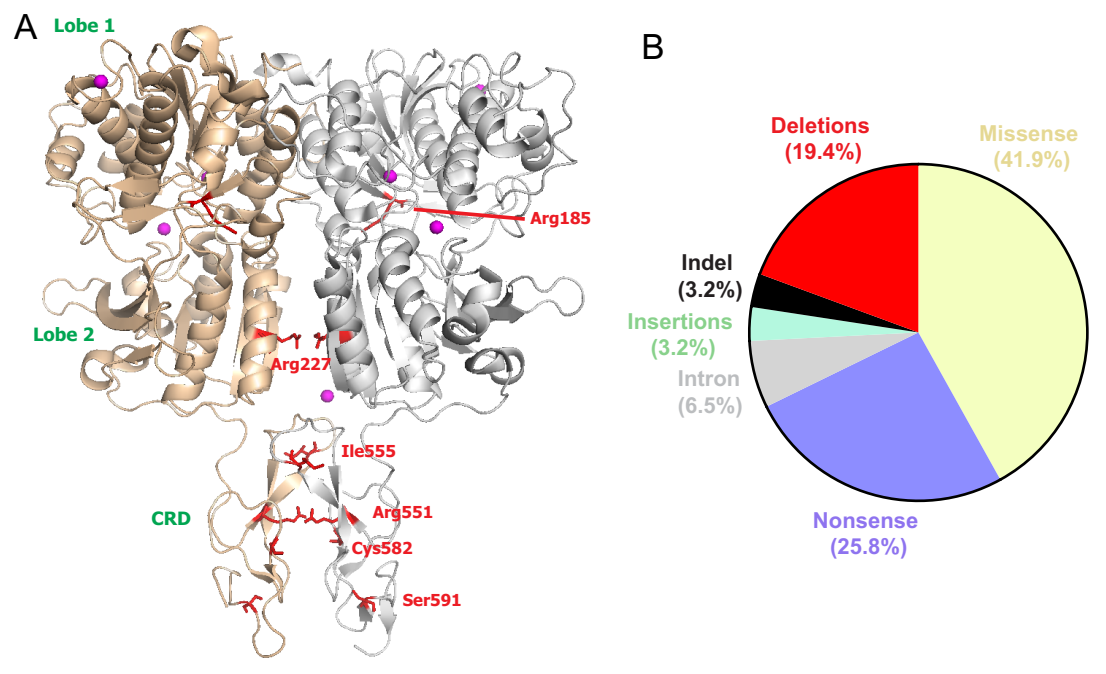

C
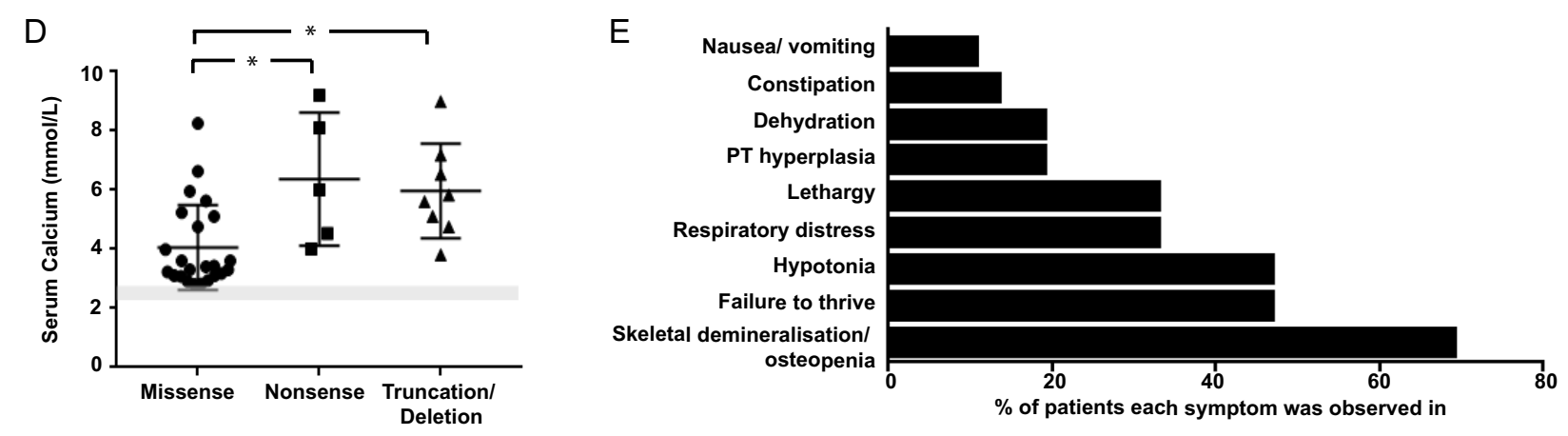

Figure 2

(A) Model showing locations of NSHPT-associated heterozygous mutations (red sticks) on the active structure of the CaSR-ECD (PDB:5K5S) (Geng et al. 2016). The six heterozygous mutations are located within domain interfaces that are critical for receptor activation. (B) Pie chart showing type of mutations described in NSHPT patients expressed as a percentage. Only the homozygous mutations are shown. The nonsense and deletion mutations lead to partial or complete loss of the TMD and C-terminus in NSHPT. Indel, insertion/deletion. (C) Serum calcium values of patients based on inheritance patterns of mutant alleles. Serum calcium concentrations are higher in homozygous and compound heterozygous patients indicating a gene dosage effect. The grey line indicates the normal range values $(2.2-2.6 \mathrm{mmol} / \mathrm{L})$. (D) Serum calcium values of patients based on type of mutation showing nonsense and truncation mutations are associated with increased serum calcium values compared to missense mutations. There is no significant difference between serum calcium values in patients with nonsense or truncation mutations. (E) Percentage of NSHPT patients each symptom was observed in. All analyses are based on published biochemistry and clinical descriptions of NSHPT mutations from 41 patients (Supplementary Table 1). Statistical analyses were performed by one-way ANOVA. $* \star \star \star x P<0.0001, * P<0.01$.

\section{Types of mutation and functional effect of NSHPT mutations}

Twenty-nine different homozygous mutations have been described in association with NSHPT, with almost half due to missense mutations (Supplementary Table 1). These missense mutations occur predominantly in the ECD $(\sim 84 \%)$, demonstrating the importance of this domain in receptor activation and maintaining structural integrity. Additionally, one homozygous NSHPT mutation (Gly768Val) occurs in ECL2 and this mutation is predicted to disrupt the tightly packed region between the CRD, ECL2 and TMD, while the only missense ICD mutation described to cause NSHPT, Arg886Trp, has an unknown effect on CaSR. The other 17 NSHPT mutations include
7 nonsense mutations, 5 frameshifts resulting in a premature stop codon, 1 deletion, 1 insertion-deletion, 2 intronic variants resulting in changes in splice sites and 1 insertion of an Alu repeat has also been reported in three families (Fig. 2B, Supplementary Table 1). All the nonsense mutations affect residues within the ECD, resulting in loss of the whole TMD and ICD, and subsequently complete loss of CaSR signalling. Similarly, many of the frameshift mutations and large deletions result in complete or partial loss of the TMD and total deletion of the ICD.

Fifteen of the NSHPT mutations have been characterised in vitro, including three of the heterozygous mutations (Supplementary Table 1). All mutations impair or abolish CaSR signalling (as measured by $\mathrm{Ca}^{2+}{ }_{\mathrm{i}}$, MAPK 
and/or $\mathrm{IP}_{3}$ assays (measuring the $\mathrm{IP}_{3}$ breakdown product $\left.\mathrm{IP}_{1}\right)$ ). The majority of the homozygous mutations (six of seven tested) reduced cell-surface expression, which may be due to failure of some CaSR mutants to complete quality control checks at the ER and Golgi (Huang \& Breitwieser 2007), while none of the heterozygous mutations tested affect cell-surface expression, indicating these mutations may impair receptor activation rather than protein expression.

\section{Clinical details and treatment of NSHPT}

Clinical biochemistry from 41 patients with NSHPT demonstrates a mean serum calcium of $4.80 \pm 1.79 \mathrm{mmol} / \mathrm{L}$ (range of $2.8-9.2 \mathrm{mmol} / \mathrm{L}$, normal range: $2.2-2.6 \mathrm{mmol} / \mathrm{L}$ ). Those individuals with homozygous mutations or compound heterozygous mutations have higher serum calcium values (mean: $5.68 \pm 1.81 \mathrm{mmol} / \mathrm{L}$ and $4.75 \pm 1.27 \mathrm{mmol} / \mathrm{L}$, respectively) than those with heterozygous mutations (mean: $3.24 \pm 0.23 \mathrm{mmol} / \mathrm{L}$ ), demonstrating a mutation dosage effect, although a wide range of serum calcium values are observed in homozygous individuals (Fig. 2C). Similarly, nonsense mutations and truncation mutations, which are likely to have a more devastating effect on receptor structure and consequently CaSR activity cause a more severe increase in serum calcium than missense mutations (Fig. 2D). PTH values were higher than the normal range in $83 \%$ of NSHPT patients.

The median age of diagnosis of NSHPT is 14 days, with a large age range between 2 days and up to several months of age. Despite this range, there was no difference in the calcium values of patients presenting early ( $<2$ weeks postpartum) and those presenting later ( $>2$ weeks after birth) (mean: $4.80 \pm 1.95$ vs $4.74 \pm 1.72 \mathrm{mmol} / \mathrm{L}$, respectively), nor was there a difference in the type of symptoms with which these individuals presented. The most commonly reported symptoms were skeletal undermineralisation and/or osteopenia (69.5\%), failure to thrive (47.2\%) and hypotonia (47.2\%) (Fig. 2E). Respiratory distress and lethargy are also commonly observed (both 33.3\%), while dehydration, constipation and nausea/vomiting are observed in $<20 \%$ in NSHPT patients (Fig. 2E). Parathyroidectomy is often the preferred treatment option in NSHPT, with bisphosphonates used to reduce hypercalcaemia prior to surgery (Mayr et al. 2016). Use of the CaSR-positive allosteric modulator, cinacalcet, which enhances the sensitivity of the receptor to $\mathrm{Ca}^{2+}{ }_{\mathrm{e}}$, has also been successful in lowering PTH and decreasing serum calcium in some NSHPT patients (Mayr et al. 2016,
Sun et al. 2018) (Supplementary Table 1). Cinacalcet has proven effective in patients with the Arg185Gln heterozygous mutation, and some homozygous patients (e.g. Arg69His); however, other patients are unresponsive (e.g. Arg680His), indicating its efficacy is genotype dependent (Mayr et al. 2016, Sun et al. 2018). Despite this caveat, cinacalcet is likely to be increasingly utilised as an initial treatment in NSHPT patients, due to its rapid effect on PTH levels and serum calcium.

\section{Key messages for NSHPT}

- The majority of NSHPT mutations are homozygous, although heterozygous cases have been described.

- Heterozygous NSHPT mutations are located in regions that are critical for receptor activation and are associated with reduced serum calcium values compared to homozygous or compound heterozygous mutations.

- Cinacalcet is an effective treatment in some patients, although parathyroidectomy is routinely performed too.

\section{Familial hypocalciuric hypercalcaemia type-1 (FHH1)}

Inactivating mutations in the CaSR also cause FHH1 (OMIM:145980), an autosomal dominant condition characterised by lifelong elevated serum calcium values, high or normal PTH concentrations and a low renal calcium excretion (Christensen et al. 2008, Eastell et al. 2014). FHH1 is usually benign and does not require treatment; however, its biochemical features have considerable overlap with typical primary hyperparathyroidism (PHPT), and often FHH is classified as a form of atypical PHPT (Marx 2018). However, unlike in typical PHPT, hypercalcaemia in FHH patients remains persistent following parathyroidectomy, and therefore, it is important to distinguish between typical PHPT and atypical forms (i.e. FHH) to avoid unnecessary surgery (Christensen et al. 2008, Eastell et al. 2014). Measurement of the urinary calcium/creatinine clearance ratio (UCCR) has been suggested as a simple biochemical diagnostic test to differentiate the two conditions with a cut-off of $<0.02$ for FHH1 (Christensen et al. 2008). However, low UCCRs (between 0.01 and 0.02) are observed in some typical PHPT patients, especially those with vitamin D deficiency or renal insufficiency; therefore, genetic analysis is still the gold standard in differentiating between FHH1 and typical PHPT (Christensen et al. 2008, Eastell et al. 2014). 
Despite this, a failure to identify a mutation in CaSR or other FHH-related genes may not indicate the patient has typical PHPT, as some FHH patients have no mutations in the currently known causative genes. Therefore, a combined approach with consideration of genetic analysis, UCCR and other symptoms may be best practice in ascertaining a correct diagnosis between FHH and typical PHPT patients.

Patients with FHH1 usually have mild hypercalcaemia; the mean serum calcium value of all FHH1 patients reported in $>200$ cases is $2.85 \pm 0.28 \mathrm{mmol} / \mathrm{L}, 31 \%$ of whom have a high serum PTH level. However, there is a wide range of serum calcium values from 2.43 to $4.48 \mathrm{mmol} / \mathrm{L}$, with 177 patients with mild hypercalcaemia, 29 patients with moderate hypercalcaemia $(3.1-3.5 \mathrm{mmol} / \mathrm{L})$, and 6 patients with severe hypercalcaemia $(>3.5 \mathrm{mmol} / \mathrm{L})$. Indeed, it is becoming increasingly recognised that CaSR loss-of-function mutations are responsible for a spectrum of hypercalcaemic disorders, from serum calcium values slightly above the normal range to severe symptomatic hypercalcaemia similar to typical PHPT (Hannan \& Thakker 2013). The majority of patients with FHH1 are asymptomatic $(\sim 71 \%)$. However, some individuals have typical symptoms of hypercalcaemia including headaches, fatigue, muscle cramps, constipation, nausea and vomiting (9\%), while other patients present with associated features including nephrocalcinosis/nephrolithiasis ( 7\%), osteoporosis and/or fractures (9\%) and pancreatitis (3.5\%). It is also possible that some of these associated symptoms are incidental and not caused by the CaSR mutation. Those individuals with symptomatic hypercalcaemia have higher serum calcium values than those that are asymptomatic $(2.97 \pm 0.38$ vs $2.79 \pm 0.17 \mathrm{mmol} / \mathrm{L}$, Fig. $3 \mathrm{~A})$, and it is likely this hypercalcaemic spectrum will become even more apparent as more population-level genetic data becomes available and the relationship between serum calcium concentration and CaSR variant status can be assessed in more detail. Treatment is not required in most cases of $\mathrm{FHH}$, although cinacalcet has been shown to be efficacious in some individuals with symptomatic hypercalcaemia (Supplementary Table 1).

\section{Genetic landscape of FHH1 mutations}

Almost 300 mutations have been reported in association with FHH1. Of these $\sim 81 \%$ are missense mutations, $6.5 \%$ are nonsense mutations, $8 \%$ are deletion mutations, while 7 intron mutations that cause splice-site changes and 7 insertion mutations have also been described (Fig. 3B, Supplementary Table 1). The majority of these FHH1
A
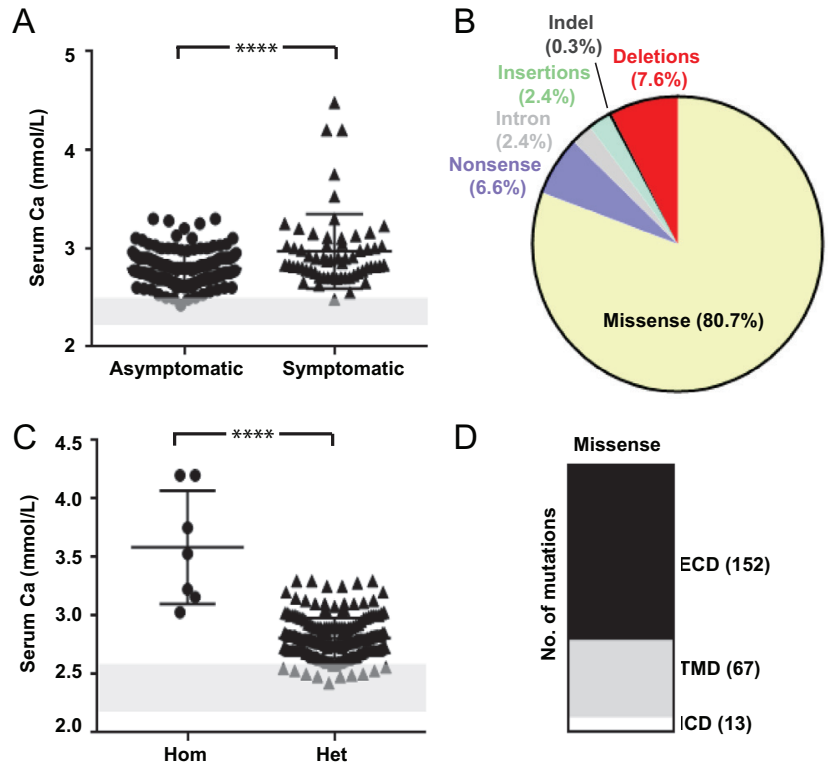

D

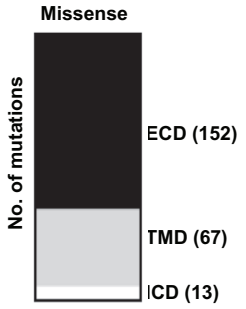

\section{Figure 3}

Genetic landscape of FHH1 mutations. (A) Mean serum calcium values of $\mathrm{FHH} 1$ patients with asymptomatic vs symptomatic hypercalcaemia. Patients were regarded as symptomatic if they presented with typical signs of hypercalcaemia (e.g. headaches, fatigue, muscle cramps, constipation, nausea and vomiting) or associated phenotypes (e.g. nephrocalcinosis/nephrolithiasis, osteoporosis and/or fractures, pancreatitis). Patients with symptomatic hypercalcaemia had higher serum calcium values than asymptomatic individuals. Grey line indicates normal range values (2.2-2.6 mmol/L). (B) Pie chart showing type of mutations described in $\mathrm{FHH} 1$ patients expressed as a percentage. Percentage of $\mathrm{FHH} 1$ patients with different types of mutation. Approximately $80 \%$ of $\mathrm{FHH} 1$ mutations are missense. (C) The majority of FHH1 mutations are heterozygous and these patients have milder hypercalcaemia than those with homozygous mutations. (D) Number of FHH1 mutations located in each domain of the CaSR. All analyses are based on published biochemistry and descriptions of $\mathrm{FHH} 1$ mutations from 290 individuals/kindreds (Supplementary Table 1). Statistical analyses were performed by Student's $t$-test. $* \star \star \star P<0.0001$.

mutations are heterozygous; however, there are a small number of cases in which homozygous mutations have been detected (Supplementary Table 1). These individuals present at an earlier age than other FHH1 patients and are born to consanguineous parents (Hannan et al. 2010). The serum calcium values for homozygous FHH1 patients are significantly greater than those in heterozygous patients (Fig. 3C). Functional analyses of $\mathrm{Ca}^{2+}{ }_{\mathrm{i}}$ show homozygous FHH1 mutants have a milder loss of function than those identified in the heterozygous state, and it is possible these mutations have a less severe effect on receptor function and consequently mutations on both alleles are necessary for an in vivo effect to become apparent (Chikatsu et al. 1999, Hannan et al. 2010). Consistent with this, the heterozygous parents of individuals with homozygous FHH1 mutations are often normocalcaemic, and the 
mutations are not predicted to affect structural integrity or receptor activation (Hannan et al. 2010).

\section{FHH1 ECD mutations}

Of the 234 missense mutants, 155 are located in the ECD, 66 in the TMD and 13 in the ICD (Fig. 3D). Missense mutations in the CaSR ECD cluster in three locations: loop 1, dimer interfaces and ligand-binding sites (Fig. 4). Nine FHH1 mutations have been identified within loop 1 which extends from Ile40 to Tyr63 and stretches across the homodimer interface to interact with a hydrophobic surface on the other protomer (Geng et al. 2016, Zhang et al. 2016) (Fig. 1, Supplementary Table 1). Of note Pro55, which is mutated to Leu55 in FHH1, forms an interaction with residues on lobe 1 of the opposite protomer and is thought to contribute to dimerization (Zhang et al. 2016). In vitro studies have shown the Leu55 mutant reduces cellsurface expression of the Pro55Leu mutant protein and impairs signalling (Chikatsu et al. 1999, White et al. 2009).

Almost 70 FHH1 mutations are located at critical domain interfaces including 28 at the homodimer interface, 24 at the hinge region between lobe 1 and lobe 2,8 at the interface between lobe 2 and the CRD and 11 at the CRD-CRD homodimer interface (Fig. 4A, Supplementary Table 1). The dimer interface has two critical functions: structural integrity of the receptor and expansion of receptor contacts following agonist-induced conformational changes, which leads to activation of the receptor (White et al. 2009, Geng et al. 2016, Zhang et al. 2016). Consistent with these functions, $31 \%$ of FHH1 dimer interface mutations disrupt cell-surface expression and all mutations tested disrupt both $\mathrm{Ca}^{2+}{ }_{\mathrm{i}}$ and MAPK activity.

The final location at which FHH1 missense mutations cluster is the ligand-binding sites (Fig. 4A, B, C, D and E). Four distinct $\mathrm{Ca}^{2+}$-binding sites have been identified in CaSR-ECD crystal structures: site 1 located at the top of lobe 1 ; site 2 in lobe 1 above the interdomain crevice; site 3 in the cleft between lobe 1 and lobe 2 and site 4 within the lobe 2-CRD interface (Fig. 4A) (Geng et al. 2016, Zhang et al. 2016). In addition, tryptophan can bind at an orthosteric site within the interdomain interface in the active state and acts as a co-agonist to facilitate ECD closure to potentiate CaSR function (Geng et al. 2016, Zhang et al. 2016). Forty-six FHH1 missense mutations map within $10 \AA$ of a $\mathrm{Ca}^{2+}$ or L-Trp-binding site, and could potentially affect ligand binding (Fig. 4B, C, D and E). Several residues have been shown to directly coordinate $\mathrm{Ca}^{2+}$-binding including Ile81 in site 1 (mutated to Thr81 and Met81 in FHH1); Thr100 and Thr145 in site 2 (both mutated to isoleucines in FHH1); Arg66 and Ser302 in site 3 (mutated to His66, Cys66 and Phe302 in FHH1) and Glu231 and Gly557 in site 4 (mutated to Lys231 and Glu557 in FHH1) (Fig. 4B, C, D and E, Supplementary Table 1). All these mutations have been shown to impair
A

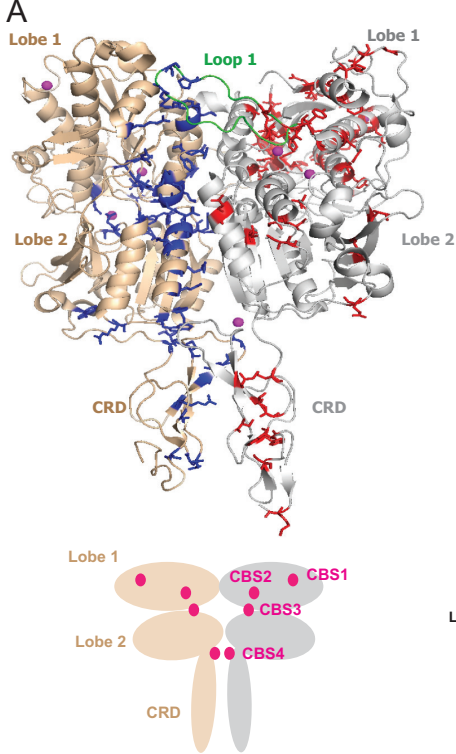

B
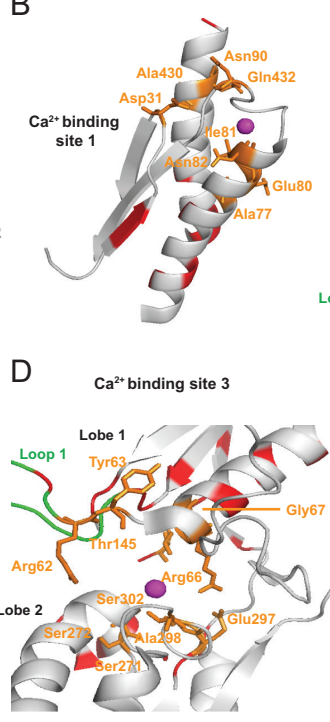

C

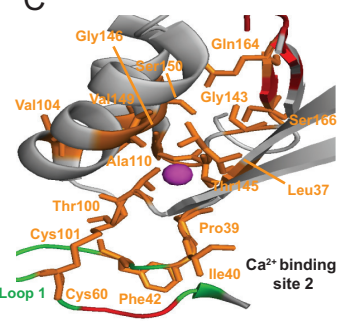

E

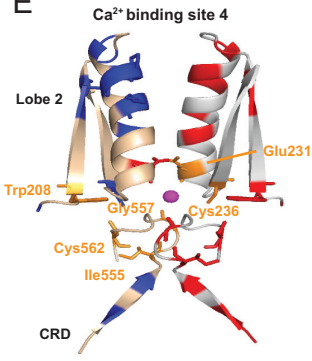

Figure 4

Clustering of $\mathrm{FHH} 1$ mutations at dimer interfaces and ligand-binding sites. (A) Top: model showing the locations of the $\mathrm{FHH} 1$-associated mutations in the active structure of the CaSR-ECD (PDB:5K5S) (Geng et al. 2016). Mutations shown in blue are located in domain interfaces including the lobe 1-lobe 2 hinge region, the CRD-CRD interface and the homodimer interface. FHH1 mutations are also located within loop 1 (green) which extends from one protomer across the homodimer interface to interact with the other protomer. The mutations shown in red are the other residues mutated by missense FHH1 mutations. Several of these mutations are located close to $\mathrm{Ca}^{2+}$-binding sites (shown as magenta spheres). Bottom: cartoon of the active CaSR showing locations of $\mathrm{Ca}^{2+-b i n d i n g ~ s i t e s ~(C B S 1-4) . ~(B, ~ C, ~ D ~ a n d ~ E) ~ C a S R ~}$ residues that are mutated in $\mathrm{FHH} 1$ and are located within $10 \AA$ of each of the four $\mathrm{Ca}^{2+}$ binding sites shown in orange. Mutations at these residues could affect ligand binding to the CaSR and receptor activation. Surrounding residues that are mutated in $\mathrm{FHH} 1$ and located $>10 \AA$ from the $\mathrm{Ca}^{2+}$-binding sites are shown in red or blue without sticks. 
receptor signalling in vitro (Geng et al. 2016, Zhang et al. 2016). Furthermore, several residues including Thr145, Tyr218, Ser296, Glu297 and Ala298, which are the site of seven FHH1 mutations, are involved in L-Trp binding, and these mutations similarly impair receptor activation (Geng et al. 2016).

\section{FHH1 mutations in the TMD}

Sixty-six FHH1 mutations are located in the TMD (Supplementary Table 1). Using the crystal structure of the related class C GPCR, mGluR5 (Dore et al. 2014), it is possible to build a homology model of the CaSR-TMD and discern the likely locations of the FHH1 mutations within the TMD (Fig. 5). Previous studies of loss-of-function mutations in other GPCRs has shown a clustering at the TM1-TM2-TM7 interface and at the TM3-TM6 interface (Stoy \& Gurevich 2015). CaSR-inactivating mutations identified in FHH1 similarly cluster in the TM1-TM2TM7 interface (16 FHH1 mutations, Fig. 5A). There is no clustering at the TM3-TM6 interface, although there are two independent groups of mutations surrounding TM3 (27 mutations) and TM6 (20 mutations) (Fig. 5B and C). Within other class C GPCRs, TM3 and TM6 undergo large ligand-induced conformational changes, which is necessary for receptor activation and G-protein coupling, and FHH1 mutations may impair these structural changes, consequently impairing receptor signalling (Binet et al. 2007, Leach et al. 2012, Xue et al. 2015).

\section{Key messages for $\mathrm{FHH}$}

- Usually associated with mild hypercalcaemia, but is increasingly becoming recognised that loss-of-function CaSR mutations are responsible for a spectrum of hypercalcaemic disorders.
- Majority of patients are asymptomatic, and those patients that have hypercalcaemic symptoms have higher serum calcium values.

- More than 300 mutations have been described to cause $\mathrm{FHH}$, the majority of which are missense.

- ECD mutations cluster in three locations: loop 1, dimer interfaces and ligand-binding sites.

- TMD mutations cluster in the TM1-TM2-TM7 interface or surrounding TM3 and TM6.

\section{CaSR gain-of-function mutations cause ADH1}

ADH1 (OMIM:601198), caused by gain-of function mutations in CaSR, is characterised by mild-to-moderate hypocalcaemia associated with inappropriately low or normal serum PTH values (Hannan \& Thakker 2013, Roszko et al. 2016). In the population of ADH1 patients described to date ( 100 patients, Supplementary Table 1$)$, the mean serum calcium value is $1.68 \pm 0.31 \mathrm{mmol} / \mathrm{L}$ with a range of $0.79-2.3 \mathrm{mmol} / \mathrm{L}$. In these patients serum PTH concentrations are inappropriately low in $76 \%$ of patients and normal in $24 \%$ of patients. Other biochemical features of ADH1 include hyperphosphatemia, hypomagnesemia and hypercalciuria (Hannan \& Thakker 2013, Roszko et al. 2016). Most ADH1 patients have a urinary calcium to creatinine ratio within or above the reference range and relative hypercalciuria rises as the low levels of PTH fail to induce calcium reabsorption from the primary filtrate at the kidney (Roszko et al. 2016). Patients with ADH1 need to be distinguished from individuals with other forms of hypoparathyroidism as treatment with vitamin D or its metabolites to correct hypocalcaemia may exacerbate hypercalciuria and nephrocalcinosis in ADH1 patients (Hannan \& Thakker 2013, Roszko et al. 2016). In asymptomatic individuals treatment is therefore avoided. In those patients with symptomatic
A

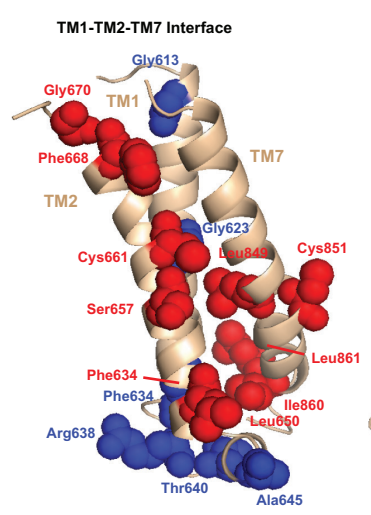

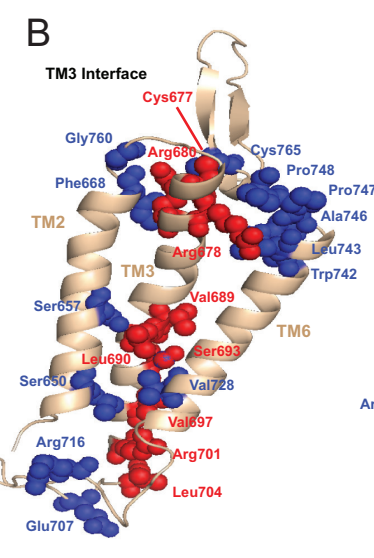

Figure 5

FHH1 mutations located in the TMD. Homology model of the CaSR-TMD based on the crystal structure of mGluR5 (PDB:4009) (Dore et al. 2014). FHH1 mutations (shown as red or blue spheres) in the CaSR cluster in three locations: $(A)$ the TM1-TM2-TM7 interface, (B) the TM3 interface and (C) the TM6 interface. Those mutant residues that do not project towards the interface or are not interacting with other residues within the interface are not shown on the model. https://jme.bioscientifica.com https://doi.org/10.1530/JME-19-0104
(C) 2019 Society for Endocrinology Published by Bioscientifica Ltd. Printed in Great Britain 
hypocalcaemia alternative treatments include thiazide diuretics, which lower urinary calcium or recombinant human PTH (Hannan \& Thakker 2013, Roszko et al. 2016). Future treatments of symptomatic ADH1 are likely to include negative allosteric modulators of the CaSR (calcilytics), which have been demonstrated to normalise calcium responses in vitro and to increase serum PTH and calcium, while reducing urinary calcium excretion in mouse models of ADH1 (Dong et al. 2015).

$\mathrm{ADH} 1$ is asymptomatic in $28 \%$ of patients. Most symptoms observed in ADH1 patients are due to neuromuscular irritability caused by hypocalcaemia and include carpopedal spasms, tetany, paraesthesia and seizures (Raue et al. 2011). Seizures have been described in $39 \%$ of $\mathrm{ADH} 1$ patients with other hypocalcaemic features reported in $41 \%$. Additionally, some patients present with associated features including basal ganglia calcifications (32\%) and nephrocalcinosis (36\%). The severity of hypocalcaemia correlates with the observance of symptomatic ADH1 with such individuals presenting with a significantly lower serum calcium concentration than those without symptoms $(1.65 \pm 0.33 \mathrm{mmol} / \mathrm{L}$ vs $1.82 \pm 0.23 \mathrm{mmol} / \mathrm{L}$, Fig. $6 \mathrm{~A})$.

\section{Genetic landscape of ADH1}

Accurate diagnosis of ADH1 requires CaSR mutational analysis. To date, 100 different mutations have been described that are associated with ADH1 (Supplementary Table 1$)$. The majority of cases $(96 \%)$ are caused by heterozygous missense mutations (Fig. 6B, Supplementary Table 1). However, one nonsense mutation (Gln934Stop) and four deletions (Ser895fsX939, del:Ser895-Val1075, Ser901fsX977 and Leu968fsX977) that occur in the ICD have also been described in ADH1. These four mutations result in loss of $>100$ amino acids within the C-terminus, indicating that this region of the CaSR is critical for receptor desensitisation or degradation. Indeed, two ubiquitin ligases, AMSH and dorfin, which reduce CaSR expression by increasing receptor degradation, have been demonstrated to bind to this region of the C-terminus (McCullough et al. 2004, Huang et al. 2006), and the ADH1 deletion mutants may increase CaSR signalling by reducing receptor degradation. Consistent with this idea, in vitro studies demonstrated that cells expressing the Ser895fsX939 and Ser901-904fsX977 mutants exhibited elevated levels of CaSR protein and increased $\mathrm{Ca}^{2+}{ }_{\mathrm{i}}$ and MAPK signalling when compared to cells expressing WT CaSR (Lienhardt et al. 2000, Obermannova et al. 2016, Maruca et al. 2017). This occurs despite loss of the region identified to bind filamin-A, an actin cytoskeletal protein that enhances CaSR-mediated activation of MAPK pathways (Zhang \& Breitwieser 2005). Therefore, many questions remain to be answered regarding how truncation of the CaSR C-terminal tail by ADH1 mutations promotes receptor signalling.

The 95 ADH1 missense mutations are predominantly located in the ECD (52 mutations) and TMD (41 mutations), with only two mutations identified in the C-terminal region (Fig. 6C). There is no correlation between serum calcium values of individuals with mutations in the ECD, TMD or C-terminus, although the range of calcium values is wider for patients with ECD mutations $(0.79-2.2 \mathrm{mmol} / \mathrm{L}$ compared to 1.18 $2.02 \mathrm{mmol} / \mathrm{L}$ for C-terminus mutations) (Fig. 6D). The two C-terminal missense mutations affect residues that are critical for facilitating $\mathrm{Ca}^{2+}{ }_{\mathrm{i}}$ responses (Bai et al. 1998, Huang et al. 2010, Lazarus et al. 2011). The first mutation Val883Met, disrupts a region that is known to interact with calmodulin and dorfin (Huang et al. 2010), while the second mutation, Thr888Met, disrupts a protein kinase C phosphorylation site that negatively regulates CaSR coupling to $\mathrm{Ca}^{2+}{ }_{\mathrm{i}}$ stores (Bai et al. 1998). Mutation of this residue impairs receptor phosphorylation and increases CaSR-mediated $\mathrm{Ca}^{2+}{ }_{\mathrm{i}}$ and pERK signalling (Bai et al. 1998, Lazarus et al. 2011).

The ECD missense mutations are clustered in three key sites: loop 2; the hinge region between lobes 1 and 2 ; and the homodimer interface, demonstrating the importance of these residues in CaSR receptor activation and signalling (Fig. 6E, Supplementary Table 1). Loop 2 stretches across the interprotomer region at each lobe 1 and stabilises dimerization (Geng et al. 2016, Zhang et al. 2016). Twenty-four ADH1 mutations have been reported within this region, and many of these residues are mutation hotspots, with some residues mutated multiple times in different patients (Supplementary Table 1). Two residues in particular, Cys129 and Cys131, are each mutated to four different amino acids, and in vitro studies have revealed these residues play a critical role in CaSR glycosylation and dimerization by forming intermolecular disulfide bonds (Fan et al. 1997). Eight ADH1 mutations are located in the hinge region between lobes 1 and 2, and thirteen mutations affect residues within the homodimer interface (Fig. 6E, Supplementary Table 1). Additionally, some of these mutations have been reported in more than one unrelated patient including Pro221Leu, reported in multiple independent cases (Supplementary Table 1). Studies of mutations affecting residues within the hinge region and homodimer 


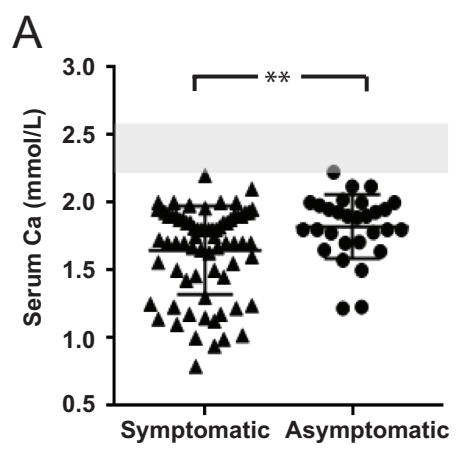

B

E

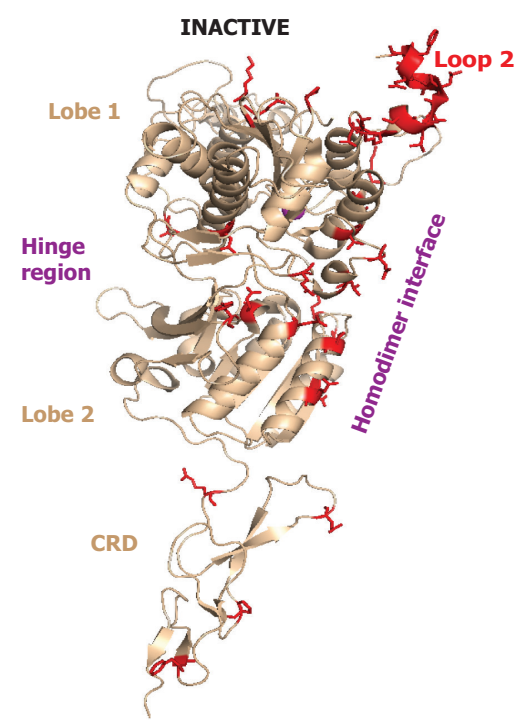

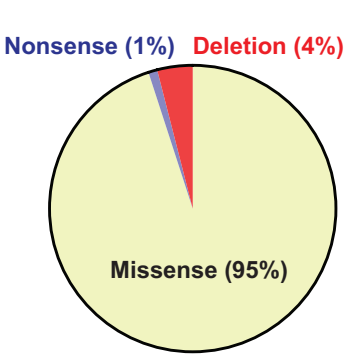

C

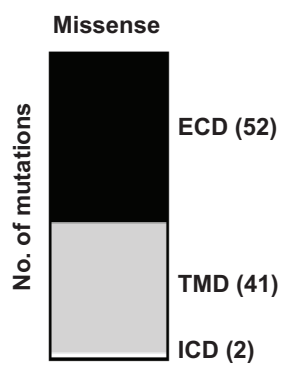

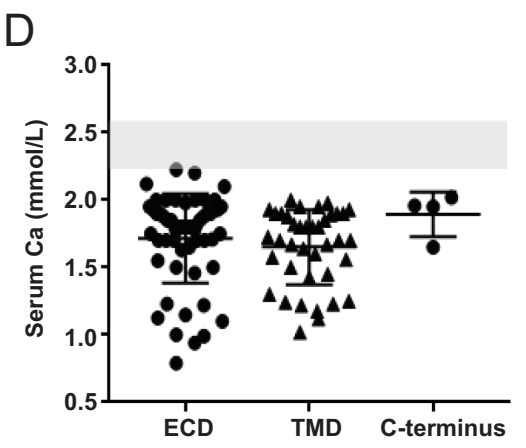
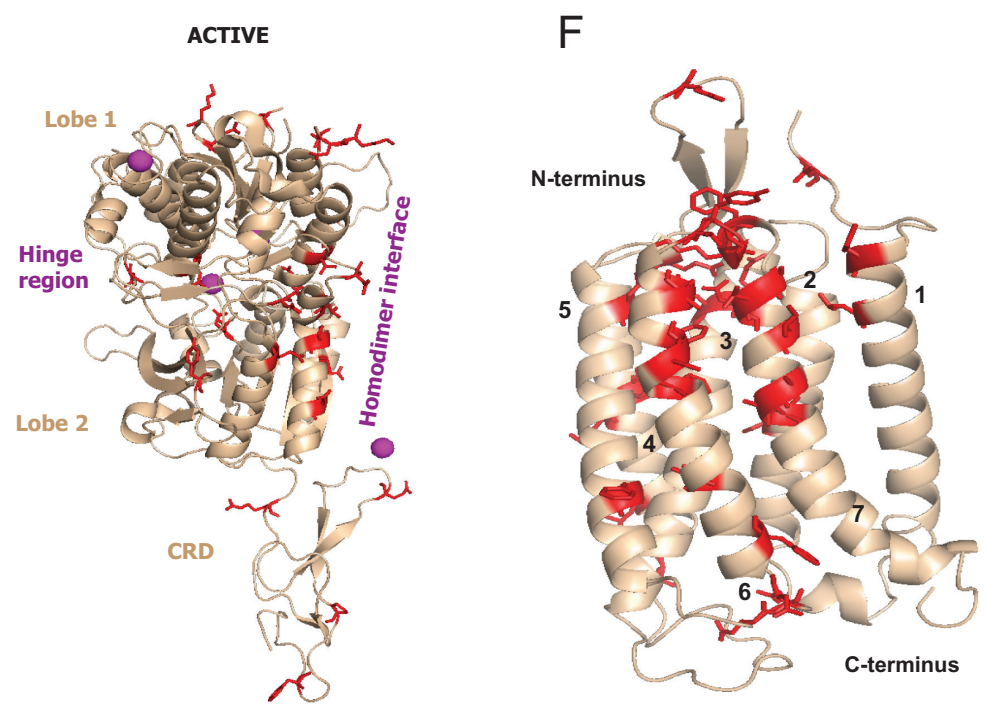

Figure 6

Genetic landscape of ADH1 mutations. (A) Mean serum calcium values of ADH1 patients with symptomatic vs asymptomatic hypocalcaemia. Patients were regarded as symptomatic if they presented with signs of hypocalcaemia (e.g. carpopedal spasms, tetany, paraesthesia and seizures) or associated phenotypes (e.g. basal ganglia calcification). Patients with symptomatic hypocalcaemia have lower serum calcium values than asymptomatic individuals. Grey line indicates normal range values $(2.2-2.6 \mathrm{mmol} / \mathrm{L})$. (B) Pie chart showing type of mutations described in ADH1 patients expressed as a percentage. The majority of mutations are missense, with a few cases of small deletions reported that affect the intracellular C-terminal region of the CaSR. (C) Location of the ADH1 missense mutations in the three CaSR domains. Similar numbers of ADH1 mutations affect the ECD and TMD of the receptor. (D) Serum calcium values of individuals with ADH1 mutations in each of the three domains of the CaSR showing no significant difference. (E) Model showing locations of the ADH-associated mutations (red sticks) in the inactive and active structures of the CaSR-ECD (PDB:5K5S) (Geng et al. 2016). ADH1 mutations cluster in loop 2, the lobe 1-lobe 2 hinge region and the homodimer interface. Conformational changes occur primarily in the lobe 2 and CRD regions on ligand-binding, leading to an increase in residue contacts between the two protomers. (F) Homology model of the CaSR-TMD based on the crystal structure of mGluR5 (PDB:4OO9) (Dore et al. 2014) generated using Swiss-Model (https://swissmodel.expasy.org/). Residues mutated in ADH1 are shown in red, $\mathrm{Ca}^{2+}$ bound to the structure is shown in magenta. The majority of ADH1 mutations are located in TM6, ECL2 and TM7, which undergo large structural changes on receptor activation in other GPCRs. Biochemical data and information on mutations was obtained from the references shown in Supplementary Table 1). Statistical analyses were performed by Student's $t$-test or one-way ANOVA. $* * P<0.01$.

interface have demonstrated these residues are important in the molecular connectivity between $\mathrm{Ca}^{2+}$-binding sites (Zhang et al. 2014). Furthermore, many of these residues undergo movement from the CaSR inactive-to-active state and are located close to ligand-binding sites (Fig. 6E) (Geng et al. 2016, Zhang et al. 2016). It is therefore likely that these mutant residues elicit a gain of function by allowing conformational changes necessary for receptor activation to occur more readily than for WT receptor, by retaining the receptor in a partially active state that is fully activated at a lower concentration of ligand than WT receptor (Fig. 6E) (Zhang et al. 2014, Geng et al. 2016, Zhang et al. 2016). Consistent with such mutations favouring a partially active state, rather than enhancing protein levels or biasing signalling, when expressed in vitro, these mutant proteins do not affect cell-surface expression and enhance both $\mathrm{Ca}^{2+}{ }_{\mathrm{i}}$ and MAPK signalling (Silve et al. 2005, Zhang et al. 2014, Gorvin et al. 2018a).

Forty-one ADH1 mutations have been identified in the CaSR transmembrane domain and have provided 
important insights into CaSR activation (Fig. 6F, Supplementary Table 1). More than 20 of these gain-offunction mutations are in the TM6-TM7 region, with 8 mutations identified in TM6, 10 in TM7, and mutations in all four of the residues comprising ECL3 that tethers these two helices (Fig. 6F, Supplementary Table 1). Mutagenesis studies have shown that residues between Ile819 and Glu837, comprising the TM6-ECL3-TM7 region, participate in CaSR activation and are thus likely to be important for maintaining the receptor in its inactive conformation (Hu et al. 2005). Moreover, studies of other class C GPCRs have shown the importance of TM6 in receptor activation and G-protein coupling (Binet et al. 2007, Xue et al. 2015). Finally, several positive allosteric modulators, bind to residues within this region, and are hypothesised to reduce the inhibitory constraints within the 7TMD to enhance sensitivity to $\mathrm{Ca}^{2+}{ }_{\mathrm{e}}$ (Hu et al. 2005). In contrast, negative allosteric modulators and FHH1 mutants such as Pro823Ala, identified in this region, are hypothesised to impede rotation of TM6 (Hu et al. 2005). Thus, multiple studies provide evidence for the importance of TM6-ECL3-TM7 in CaSR activation. This understanding of the specific residues involved in CaSR activation could facilitate the rational design of allosteric modulators that are more likely to have an effect on receptor activity than by traditional compound screens.

\section{Homozygous ADH1 mutations}

Two cases of ADH1 have been reported in which the patients had homozygous CaSR mutations. The first, a large deletion of Ser895 to Val1075 within the intracellular C-terminus (Lienhardt et al. 2000), was shown to increase $\mathrm{Ca}^{2+}{ }_{\mathrm{i}}$ responses and its possible effect on receptor degradation has been discussed in a previous section. The second mutation, Arg544Gln, was originally reported as a heterozygous mutation in an individual with FHH1 (Nissen et al. 2012). However, subsequent identification of the mutation in the homozygous state with the opposite phenotype led the authors to perform a series of in vitro experiments assessing the effect of the mutation alone and in combination with the WT receptor on both $\mathrm{Ca}^{2+}{ }_{\mathrm{i}}$ and MAPK signalling (Cavaco et al. 2018). This revealed HEK293 cells expressing the Arg544Gln mutant construct had lower $\mathrm{EC}_{50}$ values compared to cells expressing either just the WT receptor or equal amounts of WT and mutant receptor to mimic the heterozygous state (Cavaco et al. 2018). Thus, the mutation only affects CaSR signalling in the homozygous state, and in the heterozygous state, it is a benign variant. This is reflected in the public exome sequencing database, the Exome Aggregation Consortium (ExAc), which reports the heterozygous variant Arg544Gln in 96 unrelated individuals. Several other CaSR mutations have also been reported to be benign following functional testing (e.g. Thr14Ala) or due to their population frequency (e.g. Glu250Lys) (Pidasheva et al. 2005, Hannan et al. 2012). These findings highlight the importance of functionally investigating CaSR variants in vitro for the diagnosis of patients with calcaemic disorders.

\section{ADH1 with Bartter's syndrome}

Occasionally, ADH1 patients have presented with features of Bartter's syndrome including hypokalaemia, hypomagnesaemia, metabolic alkalosis and hyperaldosteronaemia (Watanabe et al. 2002). Bartter's syndrome is a heterogenous disorder caused by defects in several proteins involved in transepithelial $\mathrm{NaCl}$ transport across the thick ascending limb of the loop of Henle (Hu et al. 2002, Watanabe et al. 2002). To date, five CaSR mutations have been identified in association with ADH1 and Bartter's syndrome and the clinical presentation and onset of Bartter's symptoms differ according to the type of mutation (Supplementary Table 1). The Lys29Glu and Tyr829Cys mutations are both associated with mild hypokalaemia and a late age of onset of 22 and 17 years, respectively (Vezzoli et al. 2006, Choi et al. 2015). Despite this, hypocalcaemia presents early and these patients develop signs of advanced hypocalcaemia including nephrocalcinosis and basal ganglia calcification. In contrast, patients with the Leu125Pro, Cys131Trp and Ala843Glu CaSR mutations present with a more severe form of Bartter's syndrome characterised by the full spectrum of symptoms including hypokalaemia, hypomagnesemia, metabolic alkalosis, hyperreninaemia and hyperaldosteronaemia in early childhood (Vargas-Poussou et al. 2002). The Ala843Glu mutation is associated with potent constitutive activity when examined in vitro by multiple assays $\left(\mathrm{IP}_{3}, \mathrm{Ca}^{2+}{ }_{\mathrm{i}}\right.$ mobilisation and ERK activation) (Watanabe et al. 2002, Leach et al. 2012). Consequently, when examined in vitro, increasing doses of $\mathrm{Ca}^{2+}{ }_{\mathrm{e}}$ fail to activate the receptor as the calcium stores are rapidly depleted, and the $\mathrm{E}_{\max }$ is lower than that in cells expressing WT CaSR (Leach et al. 2012). The Ala843 residue is located within TM7 and the Glu843 mutation is hypothesised to lock the receptor in an active conformation, which is less susceptible to constraints caused by changes elsewhere in the TMD (Hu et al. 2005). Two CaSR residues, Leu125 and Cys131, located in loop 2 are mutated in both ADH1 and ADH1 with Bartter's 
syndrome. Mutation of the Leu125 residue to Pro125 causes ADH1 with Bartter's and is associated with a potent gain of functional activity in $\mathrm{Ca}^{2+}{ }_{\mathrm{i}}$ response assays which may explain the severity of this patient's phenotype (Tan et al. 2003). Mutation of this residue to Phe125, which causes $\mathrm{ADH} 1$, is associated with a severe hypocalcaemia $(0.94 \mathrm{mmol} / \mathrm{L})$, with an early age of onset at 4 days old (Cole et al. 2009), indicating this residue likely has an important role in receptor activation. Similarly, the one Cys131 mutation that is associated with both ADH1 and Bartter's syndrome has a more potent effect on $\mathrm{Ca}^{2+}{ }_{\mathrm{i}}$ signalling than other ADH1 mutations (Kinoshita et al. 2014). The mechanism by which these mutations cause such a severe effect on receptor activity is still to be elucidated.

\section{ADH}

- Is associated with more than 100 mutations, the majority of which are missense.

- Most ADH patients have symptoms of hypocalcaemia (e.g. neuromuscular irritability) or associated features such as basal ganglia calcification or nephrocalcinosis.

- The ECD missense mutations are clustered in three key sites: loop 2; the hinge region between lobes 1 and 2; and the homodimer interface.

- TMD mutations are clustered in TM6-ECL3-TM7.

- Occasionally ADH1 can be associated with a Bartter's syndrome phenotype

\section{CaSR residues harbouring both inactivating and activating mutations}

Twelve residues have been identified that are the location of both germline loss- and gain-of-function mutations that cause FHH1 and ADH1, respectively (Supplementary Table 1). Such residues have previously been termed 'switch' residues as they are thought to be important in switching the receptor from the inactive to active state and may direct CaSR signalling via the $\mathrm{Ca}^{2+}{ }_{\mathrm{i}}$ or MAPK pathways (Zhang et al. 2014, Stoy \& Gurevich 2015, Gorvin et al. 2018a). Such switch mutations are not unique to CaSR and have been observed in other GPCRs including the human arginine vasopressin receptor (Stoy \& Gurevich 2015). Structural studies comparing the active and inactive states of CaSR has demonstrated these residues are often located in regions that undergo large conformational changes upon ligand binding consistent with studies of other GPCRs (Stoy \& Gurevich 2015, Gorvin et al. 2018a). Six of the CaSR switch residues are located in critical regions within the VFTD, including the dimer interface close to loop 1 (Val104), at the lobe 1-lobe 2 hinge region (Leu173, Asn178, Pro221), and within the ligand-binding site at the hinge region (Glu297) (Geng et al. 2016, Gorvin et al. 2018a). The other five switch residues are located in the TMD clustered around TM3 and TM6, which structural studies of other class C GPCRs have revealed undergo substantial outward movement during receptor activation to accommodate G-protein coupling (Binet et al. 2007, Leach et al. 2012, Xue et al. 2015).

However, designating all residues with both inactivating and activating mutations as switch residues may be too simplistic given the range of molecular phenotypes that render a receptor as active or inactive. For example, a loss-of-function mutation may arise by several mechanisms including reduced cell-surface expression (e.g. due to ER retention), impaired GPCR-Gprotein coupling or reduced ligand binding. As such, detailed molecular profiling of each mutation may be required to determine if a residue can be designated a switch residue. Eleven of the 12 CaSR residues described with shared inactivating and activating mutations have been functionally characterised. The FHH1-associated mutations in six of these residues (Glu297, Ser657, Arg680, Met734, Asn802 and Ser820) have reduced cellsurface expression in at least one study, which is likely to cause, or contribute to, the reduction in CaSR signal transduction (Bai et al. 1996, Leach et al. 2012, Gorvin et al. 2018a). Most of these residues are located within the TMD and mutations in these residues may affect the ability of the receptor to fold efficiently and traffic to the cell surface, thus reducing the receptors exposure to agonist (Leach et al. 2012). Indeed, 17 TMD mutations reported to cause FHH1 reduce cell-surface expression in at least one study (Supplementary Table 1). However, while this is true of some mutations (Met734Arg), the intrinsic signalling capacity of other mutant CaSR proteins (Arg680Cys, Arg680His) has been shown to be retained, while others may have a gain of function but with reduced expression (Ser657Tyr) (Leach et al. 2012). Therefore, it is unlikely that all these mutations impair structural integrity of the receptors, and there must be another reason that cellsurface expression is impaired, with reduced ability to form higher-order oligomers suggested as one possible contributor (Leach et al. 2012).

\section{Biased signalling}

Biased signalling is the propensity of distinct receptor conformations to preferentially couple to specific 
signalling pathways. As such, promiscuous receptors such as the CaSR that can bind multiple ligands and couple to several G-protein subtypes can exhibit distinct profiles for different agonists (Thomsen et al. 2012). In HEK293 cells when stimulated with $\mathrm{Ca}^{2+}{ }_{\mathrm{e}}$, the CaSR preferentially couples to activate $\mathrm{IP}_{3}$ and inhibit cAMP production, rather than phosphorylation of ERK1/2 (i.e. MAPK signalling) (Thomsen et al. 2012). In contrast, diseasecausing CASR mutants located in the TMD or switch residues have been shown to switch this preferential signalling by stabilising receptor conformations that couple differentially to intracellular signalling pathways (Leach et al. 2012, Gorvin et al. 2018a,b). Many ADH1 mutants couple more strongly to $\mathrm{Ca}^{2+}{ }_{\mathrm{I}}$, while inactivating mutations signal equally via the $\mathrm{Ca}^{2+}{ }_{\mathrm{i}}$ and MAPK pathways or predominantly via MAPK pathways (Leach et al. 2012). There are exceptions to this including the constitutively active Ala843Glu mutant, which enhances basal activity of both $\mathrm{Ca}^{2+}{ }_{\mathrm{i}}$ and MAPK pathways (Watanabe et al. 2002, Leach et al. 2012). Additionally, an ADH1-associated mutant, Arg680Gly, was recently described that enhanced MAPK signalling by disrupting a transmembrane salt bridge to activate a $\beta$-arrestin-mediated pathway (Gorvin et al. 2018b). Discerning the distinct signalling profiles of some CaSR mutations that cause symptomatic hyper/ hypocalcaemia may be pertinent to the rational design of drugs to selectively regulate distinct signalling pathways (Leach et al. 2012, 2014).

\section{Future directions}

As increasingly more population-level genetic data becomes available through datasets such as ExAc and The 100,000 Genomes Project, and with whole-exome/ wholegenome sequencing used more frequently in patient diagnoses, it is likely that many more CaSR variants of unknown significance on patient health will be identified. How to approach such variants is a frequent problem, especially as pathogenicity prediction programs are often incorrect and as our understanding of receptor signalling becomes increasingly more complex. An understanding of individual residue's roles in receptor structure and activation mechanisms, combined with high-throughput, reliable functional assays, could provide additional information to allow clinician's to make more informed decisions about the likelihood of variant pathogenicity. It is likely that in future more interactions between clinicians, geneticists and researchers will be required to understand how these variants impact receptor function and human health.
In the last decade, the genetic heterogeneity of $\mathrm{FHH}$ and ADH has emerged, with mutations in the Go11 protein, by which CaSR signals, and the adaptor protein-2 sigma subunit (AP2 $\sigma)$, by which CaSR is internalized, revealed as additional contributors to calcaemic disorders. Studies of these mutations have uncovered novel mechanisms by which CaSR is internalised and demonstrated that CaSR can signal by an endosomal pathway (Gorvin et al. 2018c). Moreover, some FHH and ADH patients do not have mutations in any of these three genes and discovery of the mutant proteins in these cases is likely to yield further insights into CaSR signalling and trafficking. Understanding the mechanisms by which these novel signal pathways arise, and how receptor mutations affect these pathways are likely to provide continued insights into the CaSR for years to come.

\section{Supplementary data}

This is linked to the online version of the paper at https://doi.org/10.1530/ JME-19-0104.

\section{Declaration of interest}

The authors declare that there is no conflict of interest that could be perceived as prejudicing the impartiality of this review.

\section{Funding}

This research did not receive any specific grant from any funding agency in the public, commercial or not-for-profit sector.

\section{References}

Bai M, Quinn S, Trivedi S, Kifor O, Pearce SH, Pollak MR, Krapcho K, Hebert SC \& Brown EM 1996 Expression and characterization of inactivating and activating mutations in the human Ca2+o-sensing receptor. Journal of Biological Chemistry 271 19537-19545. (https:// doi.org/10.1074/jbc.271.32.19537)

Bai M, Trivedi S, Lane CR, Yang Y, Quinn SJ \& Brown EM 1998 Protein kinase $\mathrm{C}$ phosphorylation of threonine at position 888 in $\mathrm{Ca} 2+\mathrm{O}-$ sensing receptor $(\mathrm{CaR})$ inhibits coupling to $\mathrm{Ca} 2+$ store release. Journal of Biological Chemistry 273 21267-21275. (https://doi. org/10.1074/jbc.273.33.21267)

Binet V, Duthey B, Lecaillon J, Vol C, Quoyer J, Labesse G, Pin JP \& Prézeau L 2007 Common structural requirements for heptahelical domain function in class A and class C G protein-coupled receptors. Journal of Biological Chemistry 282 12154-12163. (https://doi. org/10.1074/jbc.M611071200)

Brown EM, Gamba G, Riccardi D, Lombardi M, Butters R, Kifor O, Sun A, Hediger MA, Lytton J \& Hebert SC 1993 Cloning and characterization of an extracellular $\mathrm{Ca}(2+)$-sensing receptor from bovine parathyroid. Nature 366 575-580. (https://doi. org/10.1038/366575a0)

Cavaco BM, Canaff L, Nolin-Lapalme A, Vieira M, Silva TN, Saramago A, Domingues R, Rutter MM, Hudon J, Gleason JL, et al. 2018 Homozygous calcium-sensing receptor polymorphism R544Q
(C) 2019 Society for Endocrinology Published by Bioscientifica Ltd. Printed in Great Britain 
presents as hypocalcemic hypoparathyroidism. Journal of Clinical Endocrinology and Metabolism 103 2879-2888. (https://doi. org/10.1210/jc.2017-02407)

Chikatsu N, Fukumoto S, Suzawa M, Tanaka Y, Takeuchi Y, Takeda S, Tamura Y, Matsumoto T \& Fujita T 1999 An adult patient with severe hypercalcaemia and hypocalciuria due to a novel homozygous inactivating mutation of calcium-sensing receptor. Clinical Endocrinology 50 537-543. (https://doi. org/10.1046/j.1365-2265.1999.00729.x)

Choi KH, Shin CH, Yang SW \& Cheong HI 2015 Autosomal dominant hypocalcemia with Bartter syndrome due to a novel activating mutation of calcium sensing receptor, Y829C. Korean Journal of Pediatrics 58 148-153. (https://doi.org/10.3345/kjp.2015.58.4.148)

Christensen SE, Nissen PH, Vestergaard P, Heickendorff L, Brixen K \& Mosekilde L 2008 Discriminative power of three indices of renal calcium excretion for the distinction between familial hypocalciuric hypercalcaemia and primary hyperparathyroidism: a follow-up study on methods. Clinical Endocrinology 69 713-720. (https://doi. org/10.1111/j.1365-2265.2008.03259.x)

Cole DE, Yun FH, Wong BY, Shuen AY, Booth RA, Scillitani A, Pidasheva S, Zhou X, Canaff L \& Hendy GN 2009 Calcium-sensing receptor mutations and denaturing high performance liquid chromatography. Journal of Molecular Endocrinology 42 331-339. (https://doi.org/10.1677/JME-08-0164)

Conigrave AD 2016 The calcium-sensing receptor and the parathyroid: past, present, future. Frontiers in Physiology 7 563. (https://doi. org/10.3389/fphys.2016.00563)

Dong B, Endo I, Ohnishi Y, Kondo T, Hasegawa T, Amizuka N, Kiyonari H, Shioi G, Abe M, Fukumoto S, et al. 2015 Calcilytic ameliorates abnormalities of mutant calcium-sensing receptor (CaSR) knock-in mice mimicking autosomal dominant hypocalcemia (ADH). Journal of Bone and Mineral Research 30 1980-1993. (https://doi. org/10.1002/jbmr.2551)

Dore AS, Okrasa K, Patel JC, Serrano-Vega M, Bennett K, Cooke RM, Errey JC, Jazayeri A, Khan S, Tehan B, et al. 2014 Structure of class C GPCR metabotropic glutamate receptor 5 transmembrane domain. Nature 511 557-562. (https://doi.org/10.1038/nature13396)

Eastell R, Brandi ML, Costa AG, D'Amour P, Shoback DM \& Thakker RV 2014 Diagnosis of asymptomatic primary hyperparathyroidism: proceedings of the Fourth International Workshop. Journal of Clinical Endocrinology and Metabolism 99 3570-3579. (https://doi. org/10.1210/jc.2014-1414)

Fan G, Goldsmith PK, Collins R, Dunn CK, Krapcho KJ, Rogers KV \& Spiegel AM 1997 N-linked glycosylation of the human Ca2+ receptor is essential for its expression at the cell surface. Endocrinology 138 1916-1922. (https://doi.org/10.1210/endo.138.5.5131)

Geng Y, Mosyak L, Kurinov I, Zuo H, Sturchler E, Cheng TC, Subramanyam P, Brown AP, Brennan SC, Mun HC, et al. 2016 Structural mechanism of ligand activation in human calcium-sensing receptor. ELife 5. (https://doi.org/10.7554/eLife.13662)

Gorvin CM, Frost M, Malinauskas T, Cranston T, Boon H, Siebold C, Jones EY, Hannan FM \& Thakker RV 2018a Calcium-sensing receptor residues with loss- and gain-of-function mutations are located in regions of conformational change and cause signalling bias. Human Molecular Genetics 27 3720-3733. (https://doi.org/10.1093/hmg/ ddy263)

Gorvin CM, Hannan FM, Cranston T, Valta H, Makitie O, SchalinJantti C \& Thakker RV $2018 b$ Cinacalcet rectifies hypercalcemia in a patient with familial hypocalciuric hypercalcemia Type 2 (FHH2) caused by a germline loss-of-function Galpha11 mutation. Journal of Bone and Mineral Research 33 32-41. (https://doi.org/10.1002/ jbmr.3241)

Gorvin CM, Rogers A, Hastoy B, Tarasov AI, Frost M, Sposini S, Inoue A, Whyte MP, Rorsman P, Hanyaloglu AC, et al. 2018c AP2sigma mutations impair calcium-sensing receptor trafficking and signaling, and show an endosomal pathway to spatially direct G-protein selectivity. Cell Reports 22 1054-1066. (https://doi.org/10.1016/j. celrep.2017.12.089)

Hannan FM \& Thakker RV 2013 Calcium-sensing receptor (CaSR) mutations and disorders of calcium, electrolyte and water metabolism. Best Practice and Research. Clinical Endocrinology and Metabolism 27 359-371. (https://doi.org/10.1016/j.beem.2013.04.007)

Hannan FM, Nesbit MA, Christie PT, Lissens W, Van der Schueren B, Bex M, Bouillon R \& Thakker RV 2010 A homozygous inactivating calcium-sensing receptor mutation, Pro339Thr, is associated with isolated primary hyperparathyroidism: correlation between location of mutations and severity of hypercalcaemia. Clinical Endocrinology 73 715-722. (https://doi.org/10.1111/j.1365-2265.2010.03870.x)

Hannan FM, Nesbit MA, Zhang C, Cranston T, Curley AJ, Harding B, Fratter C, Rust N, Christie PT, Turner JJ, et al. 2012 Identification of 70 calcium-sensing receptor mutations in hyper- and hypo-calcaemic patients: evidence for clustering of extracellular domain mutations at calcium-binding sites. Human Molecular Genetics 21 2768-2778. (https://doi.org/10.1093/hmg/dds105)

Ho C, Conner DA, Pollak MR, Ladd DJ, Kifor O, Warren HB, Brown EM, Seidman JG \& Seidman CE 1995 A mouse model of human familial hypocalciuric hypercalcemia and neonatal severe hyperparathyroidism. Nature Genetics 11 389-394. (https://doi. org/10.1038/ng1295-389)

Hu J, Mora S, Colussi G, Proverbio MC, Jones KA, Bolzoni L, De Ferrari ME, Civati G \& Spiegel AM 2002 Autosomal dominant hypocalcemia caused by a novel mutation in the loop 2 region of the human calcium receptor extracellular domain. Journal of Bone and Mineral Research 17 1461-1469. (https://doi.org/10.1359/ jbmr.2002.17.8.1461)

Hu J, McLarnon SJ, Mora S, Jiang J, Thomas C, Jacobson KA \& Spiegel AM 2005 A region in the seven-transmembrane domain of the human $\mathrm{Ca} 2+$ receptor critical for response to Ca2+. Journal of Biological Chemistry 280 5113-5120. (https://doi.org/10.1074/jbc.M413403200)

Huang Y \& Breitwieser GE 2007 Rescue of calcium-sensing receptor mutants by allosteric modulators reveals a conformational checkpoint in receptor biogenesis. Journal of Biological Chemistry 282 9517-9525. (https://doi.org/10.1074/jbc.M609045200)

Huang Y, Niwa J, Sobue G \& Breitwieser GE 2006 Calcium-sensing receptor ubiquitination and degradation mediated by the E3 ubiquitin ligase dorfin. Journal of Biological Chemistry 281 11610-11617. (https://doi.org/10.1074/jbc.M513552200)

Huang Y, Zhou Y, Wong HC, Castiblanco A, Chen Y, Brown EM \& Yang JJ 2010 Calmodulin regulates Ca2+-sensing receptor-mediated $\mathrm{Ca} 2+$ signaling and its cell surface expression. Journal of Biological Chemistry 285 35919-35931. (https://doi.org/10.1074/jbc. M110.147918)

Kinoshita Y, Hori M, Taguchi M, Watanabe S \& Fukumoto S 2014 Functional activities of mutant calcium-sensing receptors determine clinical presentations in patients with autosomal dominant hypocalcemia. Journal of Clinical Endocrinology and Metabolism 99 E363-E368. (https://doi.org/10.1210/jc.2013-3430)

Lazarus S, Pretorius CJ, Khafagi F, Campion KL, Brennan SC, Conigrave AD, Brown EM \& Ward DT 2011 A novel mutation of the primary protein kinase $\mathrm{C}$ phosphorylation site in the calcium-sensing receptor causes autosomal dominant hypocalcemia. European Journal of Endocrinology 164 429-435. (https://doi.org/10.1530/EJE-10-0907)

Leach K, Wen A, Davey AE, Sexton PM, Conigrave AD \& Christopoulos A 2012 Identification of molecular phenotypes and biased signaling induced by naturally occurring mutations of the human calcium-sensing receptor. Endocrinology 153 4304-4316. (https://doi.org/10.1210/en.2012-1449)

Leach K, Sexton PM, Christopoulos A \& Conigrave AD 2014 Engendering biased signalling from the calcium-sensing receptor for the pharmacotherapy of diverse disorders. British Journal of Pharmacology 171 1142-1155. (https://doi.org/10.1111/ bph.12420) 
Lienhardt A, Garabedian M, Bai M, Sinding C, Zhang Z, Lagarde JP, Boulesteix J, Rigaud M, Brown EM \& Kottler ML 2000 A large homozygous or heterozygous in-frame deletion within the calciumsensing receptor's carboxylterminal cytoplasmic tail that causes autosomal dominant hypocalcemia. Journal of Clinical Endocrinology and Metabolism 85 1695-1702. (https://doi.org/10.1210/ jcem.85.4.6570)

Maruca K, Brambilla I, Mingione A, Bassi L, Capelli S, Brasacchio C, Soldati L, Cisternino M \& Mora S 2017 Autosomal dominant hypocalcemia due to a truncation in the C-tail of the calciumsensing receptor. Molecular and Cellular Endocrinology 439 187-193. (https://doi.org/10.1016/j.mce.2016.08.032)

Marx SJ 2018 Familial hypocalciuric hypercalcemia as an atypical form of primary hyperparathyroidism. Journal of Bone and Mineral Research 33 27-31. (https://doi.org/10.1002/jbmr.3339)

Mayr B, Schnabel D, Dorr HG \& Schofl C 2016 GENETICS IN ENDOCRINOLOGY: gain and loss of function mutations of the calcium-sensing receptor and associated proteins: current treatment concepts. European Journal of Endocrinology 174 R189-R208. (https:// doi.org/10.1530/EJE-15-1028)

McCullough J, Clague MJ \& Urbe S 2004 AMSH is an endosomeassociated ubiquitin isopeptidase. Journal of Cell Biology 166 487-492. (https://doi.org/10.1083/jcb.200401141)

Nemeth EF \& Scarpa A 1987 Rapid mobilization of cellular Ca2+ in bovine parathyroid cells evoked by extracellular divalent cations. Evidence for a cell surface calcium receptor. Journal of Biological Chemistry 262 5188-5196.

Nissen PH, Christensen SE, Ladefoged SA, Brixen K, Heickendorff L \& Mosekilde L 2012 Identification of rare and frequent variants of the CASR gene by high-resolution melting. Clinica Chimica Acta $\mathbf{4 1 3}$ 605-611. (https://doi.org/10.1016/j.cca.2011.12.004)

Nyweide K, Feldman KW, Gunther DF, Done S, Lewis C \& Van Eenwyk C 2006 Hypocalciuric hypercalcemia presenting as neonatal rib fractures: a newly described mutation of the calcium-sensing receptor gene. Pediatric Emergency Care 22 722-724. (https://doi. org/10.1097/01.pec.0000238747.19477.d3)

Obermannova B, Sumnik Z, Dusatkova P, Cinek O, Grant M, Lebl J \& Hendy GN 2016 Novel calcium-sensing receptor cytoplasmic tail deletion mutation causing autosomal dominant hypocalcemia: molecular and clinical study. European Journal of Endocrinology 174 K1-K11. (https://doi.org/10.1530/EJE-15-1216)

Pidasheva S, Canaff L, Simonds WF, Marx SJ \& Hendy GN 2005 Impaired cotranslational processing of the calcium-sensing receptor due to signal peptide missense mutations in familial hypocalciuric hypercalcemia. Human Molecular Genetics 14 1679-1690. (https://doi. org/10.1093/hmg/ddi176)

Pollak MR, Brown EM, Chou YH, Hebert SC, Marx SJ, Steinmann B, Levi T, Seidman CE \& Seidman JG 1993 Mutations in the human $\mathrm{Ca}(2+)$-sensing receptor gene cause familial hypocalciuric hypercalcemia and neonatal severe hyperparathyroidism. Cell $\mathbf{7 5}$ 1297-1303. (https://doi.org/10.1016/0092-8674(93)90617-Y)

Pollak MR, Chou YH, Marx SJ, Steinmann B, Cole DE, Brandi ML, Papapoulos SE, Menko FH, Hendy GN \& Brown EM 1994 Familial hypocalciuric hypercalcemia and neonatal severe hyperparathyroidism. Effects of mutant gene dosage on phenotype. Journal of Clinical Investigation 93 1108-1112. (https://doi. org/10.1172/JCI117062)

Raue F, Pichl J, Dorr HG, Schnabel D, Heidemann P, Hammersen G, Jaursch-Hancke C, Santen R, Schofl C, Wabitsch M, et al. 2011 Activating mutations in the calcium-sensing receptor: genetic and clinical spectrum in 25 patients with autosomal dominant hypocalcaemia - a German survey. Clinical Endocrinology 75 760-765. (https://doi.org/10.1111/j.1365-2265.2011.04142.x)

Reh CM, Hendy GN, Cole DE \& Jeandron DD 2011 Neonatal hyperparathyroidism with a heterozygous calcium-sensing receptor (CASR) R185Q mutation: clinical benefit from Cinacalcet. Journal of
Clinical Endocrinology and Metabolism 96 E707-E712. (https://doi. org/10.1210/jc.2010-1306)

Roszko KL, Bi RD \& Mannstadt M 2016 Autosomal dominant hypocalcemia (hypoparathyroidism) types 1 and 2. Frontiers in Physiology 7 458. (https://doi.org/10.3389/fphys.2016.00458)

Shoback DM, Membreno LA \& McGhee JG 1988 High calcium and other divalent cations increase inositol trisphosphate in bovine parathyroid cells. Endocrinology 123 382-389. (https://doi. org/10.1210/endo-123-1-382)

Silve C, Petrel C, Leroy C, Bruel H, Mallet E, Rognan D \& Ruat M 2005 Delineating a $\mathrm{Ca} 2+$ binding pocket within the Venus flytrap module of the human calcium-sensing receptor. Journal of Biological Chemistry 280 37917-37923. (https://doi.org/10.1074/jbc.M506263200)

Stoy H \& Gurevich VV 2015 How genetic errors in GPCRs affect their function: possible therapeutic strategies. Genes and Diseases 2 108-132. (https://doi.org/10.1016/j.gendis.2015.02.005)

Sun X, Huang L, Wu J, Tao Y \& Yang F 2018 Novel homozygous inactivating mutation of the calcium-sensing receptor gene in neonatal severe hyperparathyroidism responding to Cinacalcet therapy: A case report and literature review. Medicine 97 e13128. (https://doi.org/10.1097/MD.0000000000013128)

Taki K, Kogai T, Sakumoto J, Namatame T \& Hishinuma A 2015 Familial hypocalciuric hypercalcemia with a de novo heterozygous mutation of calcium-sensing receptor. Endocrinology, Diabetes and Metabolism Case Reports 2015 150016. (https://doi.org/10.1530/ EDM-15-0016)

Tan YM, Cardinal J, Franks AH, Mun HC, Lewis N, Harris LB, Prins JB \& Conigrave AD 2003 Autosomal dominant hypocalcemia: a novel activating mutation (E604K) in the cysteine-rich domain of the calcium-sensing receptor. Journal of Clinical Endocrinology and Metabolism 88 605-610. (https://doi.org/10.1210/jc.2002-020081)

Thomsen AR, Hvidtfeldt M \& Brauner-Osborne H 2012 Biased agonism of the calcium-sensing receptor. Cell Calcium 51 107-116. (https:// doi.org/10.1016/j.ceca.2011.11.009)

Toke J, Czirjak G, Patocs A, Enyedi B, Gergics P, Csakvary V, Enyedi P \& Toth M 2007 Neonatal severe hyperparathyroidism associated with a novel de novo heterozygous $\mathrm{R} 551 \mathrm{~K}$ inactivating mutation and a heterozygous A986S polymorphism of the calcium-sensing receptor gene. Clinical Endocrinology 67 385-392. (https://doi. org/10.1111/j.1365-2265.2007.02896.x)

Vargas-Poussou R, Huang C, Hulin P, Houillier P, Jeunemaitre X, Paillard M, Planelles G, Dechaux M, Miller RT \& Antignac C 2002 Functional characterization of a calcium-sensing receptor mutation in severe autosomal dominant hypocalcemia with a Bartter-like syndrome. Journal of the American Society of Nephrology $\mathbf{1 3}$ 2259-2266. (https://doi.org/10.1097/01.asn.0000025781.16723.68)

Vezzoli G, Arcidiacono T, Paloschi V, Terranegra A, Biasion R, Weber G, Mora S, Syren ML, Coviello D, Cusi D, et al. 2006 Autosomal dominant hypocalcemia with mild type 5 Bartter syndrome. Journal of Nephrology 19 525-528.

Watanabe S, Fukumoto S, Chang H, Takeuchi Y, Hasegawa Y, Okazaki R, Chikatsu N \& Fujita T 2002 Association between activating mutations of calcium-sensing receptor and Bartter's syndrome. Lancet 360 692-694. (https://doi.org/10.1016/S0140-6736(02)09842-2)

White E, McKenna J, Cavanaugh A \& Breitwieser GE 2009 Pharmacochaperone-mediated rescue of calcium-sensing receptor loss-of-function mutants. Molecular Endocrinology 23 1115-1123. (https://doi.org/10.1210/me.2009-0041)

Wystrychowski A, Pidasheva S, Canaff L, Chudek J, Kokot F, Wiecek A \& Hendy GN 2005 Functional characterization of calcium-sensing receptor codon 227 mutations presenting as either familial (benign) hypocalciuric hypercalcemia or neonatal hyperparathyroidism. Journal of Clinical Endocrinology and Metabolism 90 864-870. (https:// doi.org/10.1210/jc.2004-1791)

Xue L, Rovira X, Scholler P, Zhao H, Liu J, Pin JP \& Rondard P 2015 Major ligand-induced rearrangement of the heptahelical domain 
interface in a GPCR dimer. Nature Chemical Biology 11 134-140. (https://doi.org/10.1038/nchembio.1711)

Zhang M \& Breitwieser GE 2005 High affinity interaction with filamin A protects against calcium-sensing receptor degradation. Journal of Biological Chemistry 280 11140-11146. (https://doi.org/10.1074/jbc. M412242200)

Zhang C, Mulpuri N, Hannan FM, Nesbit MA, Thakker RV, Hamelberg D, Brown EM \& Yang JJ 2014 Role of Ca2+ and L-Phe in regulating functional cooperativity of disease-associated "toggle" calciumsensing receptor mutations. PLOS ONE 9 e113622. (https://doi. org/10.1371/journal.pone.0113622)

Zhang C, Zhang T, Zou J, Miller CL, Gorkhali R, Yang JY, Schilmiller A, Wang S, Huang K, Brown EM, et al. 2016 Structural basis for regulation of human calcium-sensing receptor by magnesium ions and an unexpected tryptophan derivative co-agonist. Science Advances 2 e1600241. (https://doi.org/10.1126/sciadv.1600241)

Received in final form 4 June 2019

Accepted 11 June 2019

Accepted Preprint published online 11 June 2019
(C) 2019 Society for Endocrinology Published by Bioscientifica Ltd. Printed in Great Britain 